\title{
Traditional Tales and Modernised Folk Literature
}

Every culture has traditional tales, and this is our homage to them. Stories from oral traditions appear in many forms but there are interesting similarities in some stories to those found across different cultures. Originally, traditional tales were not solely intended for children; they were created for the education and entertainment of young and old. Yet, children now enjoy these tales because they are great stories, usually short, with fast-moving plots that spark the imagination. Many are humorous, informative, and end happily ever after.

Traditional literature is a window into the culture that created it, allowing its audiences to explore particular values and beliefs from that society as well as references to language and setting. We note that many of the Canadian picture books published since 2017 focus on content developed by Indigenous authors and illustrators. Sharing these tales with children is an important part of ensuring the health and longevity of local cultures. The production of traditional literature from immigrant cultures is, however, lagging, and we encourage publishers to also embrace these perspectives as we seek commonalities to embrace in stories around the world.

Many of the books in this collection present creation stories or trickster stories. Creation stories explain something from the natural world; trickster stories present heroes - often personified animals - that cunningly employ their wits to get their way or complete a task. We present the picture books in this chapter in two sections: traditional tales, and modern tales based on traditional patterns. The modern stories call to mind particular roots in folktales, fairy tales, legends, or myths.

Where not otherwise indicated, the name of the author(s) appears first under each title, and the illustrator last.

(C) BEVERLEY BRENNA, RICHARD DIONNE AND THERESA TAVARES, 2021

DOI: $10.1163 / 9789004465107 \_004$

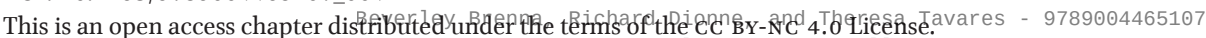




\section{Minegoo Mniku: the Mi'kmaq Creation Story of Prince Edward Island = Epekewitkewey A'tukwaqn Sandra L. Dodge, translated by Georgina Francis}

In both the Mi'kmaq language and English, Dodge shares how the Great Spirit creates Kluskap, the Mi'kmaq people, and Mine-

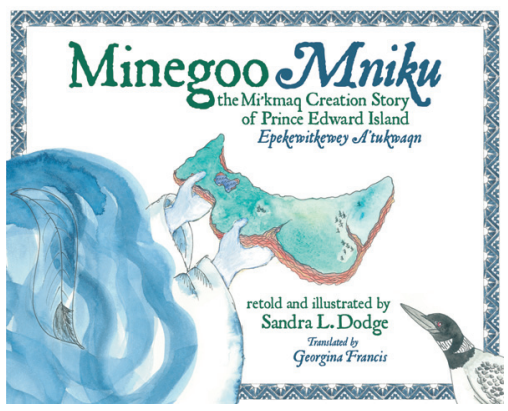
goo itself. Her watercolour illustrations are both dreamy and bold, and borders on each page are based on Mi'kmaq quill patterns. A key purpose of this book is to help keep the Mi'kmaq culture and language alive. For ages $5^{-9+}$.

\section{The Fox Wife}

\section{Beatrice Deer}

and D.J.Herron

This story is an adaptation of a traditional Inuit tale about Irniq and his wife - a shapeshifting fox. Instead of being content with what he has, Irniq is curious and his repeated questions end up driving his fox wife away. Based

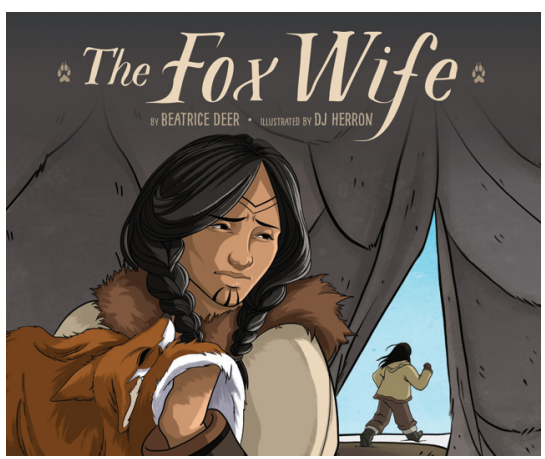
on musician Beatrice Deer's song "Fox,"

the book borrows the use of graphic novel cues, including speech bubbles and a narrator's box, along with narration more typical of picture books. For ages $5^{-9+}$ 
Sukaq and the Raven

Roy Goose, Kerry McCluskey

and Soyeon Kim

Sukaq often drifts off to sleep listening to his mother tell him stories. But this time, he is suddenly whisked off by an enormous raven to observe how the entire world is formed. The creation story from Inuit storyteller Roy Goose is brought to print through co-author Kerry McCluskey's retelling and Soyeon Kim's threedimensional dioramas of combined

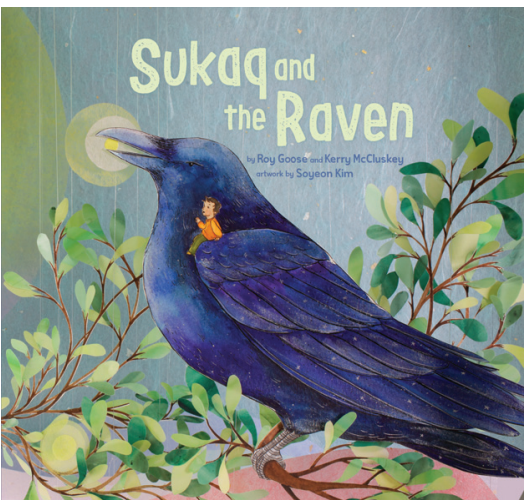
sketches and painting. For ages $5^{-8}$.

Peg Bearskin: A Traditional

Newfoundland Tale

Philip Dinn, Andy Jones

and Denise Gallagher

adapted from a tale told by

Mrs. Elizabeth Brewster

Peg is a feisty, hairy protagonist who tricks a witch to find a husband for herself and her two comely sisters. This story originated from a specific part of Placentia Bay, Newfoundland, and it shares similarities with Grimm's fairy tale, The Frog Prince as well as William Steig's picture

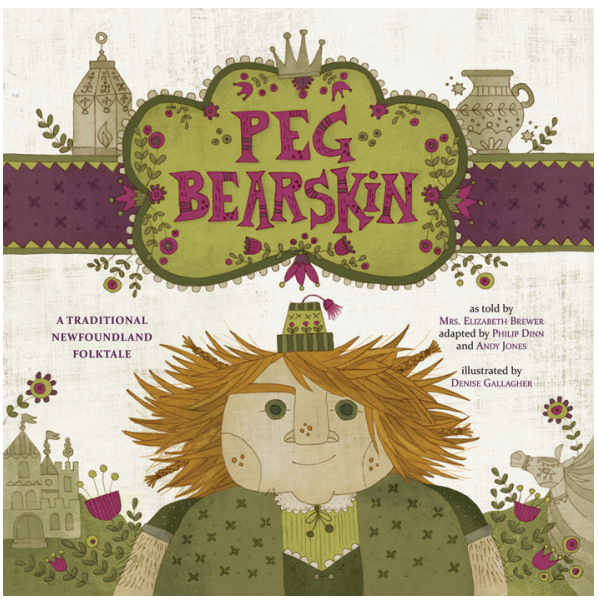
book, Shrek! For ages $5^{-9+}$. 


\section{The Walrus and the Caribou \\ Maika Harper \\ and Marcus Cutler}

This picture book is based on a traditional Inuit story passed forward orally in Arctic communities about the origin of the caribou and the walrus. An Inuit woman with the power to create life uses her garments to create these two animals. At first the animals look very different than they do in present day. Maika Harper's introduction emphasises that versions of this story can be found across the Artic, and a glossary at the back contains information about pronunciation of Inuktitut sounds. For ages $5^{-9+}$.

\section{Gifts from Raven}

Kung Jaadee

and Jessika von Innerebner

Kung Jaadee is a traditional Haida storyteller, writer, Haida language teacher, singer, and drummer from Haida Gwaii, in northern British Columbia. In this book she uses rhyming couplets to share how Raven has given each of us a unique talent or passion to share with the world. For ages 4-6.

\section{The Circle of Caring and Sharing \\ Theresa "Corky" Larsen-Jonasson \\ and Jessika von Innerebner}

This picture book uses rhyming couplets to identify how a sharing circle can help unite a community of animals. Author Theresa "Corky" Larsen-Jonasson is a respected elder, as identified by her community, with roots in Red Deer, Didsbury, and Maskwacis First Nations in Alberta. The last page of the book presents six Plains Cree Animals and their phonetic pronunciations. For ages 4-6. 
Red Sky at Night

Elly MacKay

MacKay's distinctive paper and ink illustrations, set into three dimensions and photographed, carry the storyline as Grandpa takes his grandchildren on a fishing trip. The text itself is composed of sayings about the weather. The introduction tells readers that

\section{RED SKY AT NIGHT}

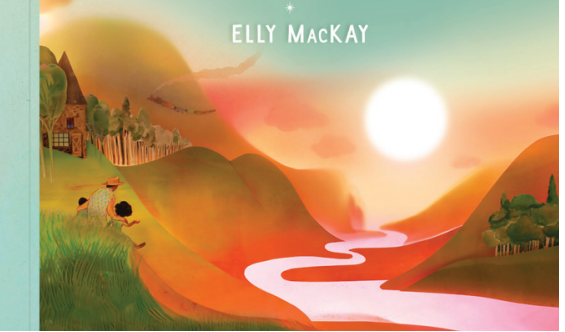
long ago, people looked for clues in nature to predict the weather, and the very first saying cited is the classic, "Red skies at night, sailor's delight." For ages 3-8.

\section{Takannaaluk \\ Herve Paniaq \\ and Germaine Arnaktauyok}

As a young girl, Takannaaluk is tricked into marrying a sea bird posing as a man, and she comes to be both feared and respected as the mother of the sea mammals. Her story is brought to life here in both Inuktitut and English by elder Herve Paniaq and Inuit artist Germaine Arnaktauyok. For ages 7-9+.

\section{The Origin of Day and Night}

Paula Ikuutaq Rumbolt

and Lenny Lishchenko

Tiri, an Artic fox, and Ukaliq, an Arctic hare, separately control the setting and rising of the sun. But... one wants darkness to prevail while the other wants daylight. This story has been communicated orally for hundreds of years in the tradition of Inuit mythology. Paula Ikuutaq

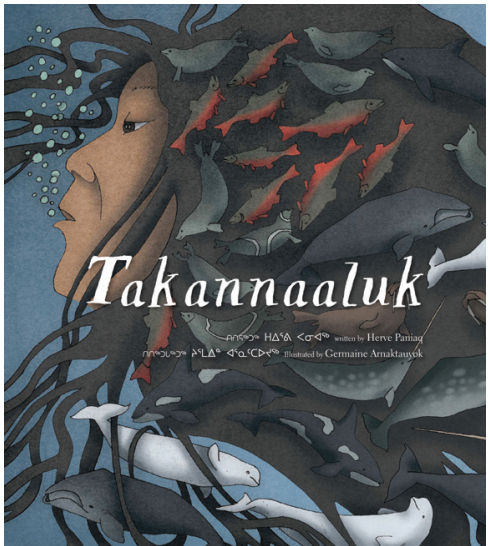
Rumbolt, an elementary school Inuktitut

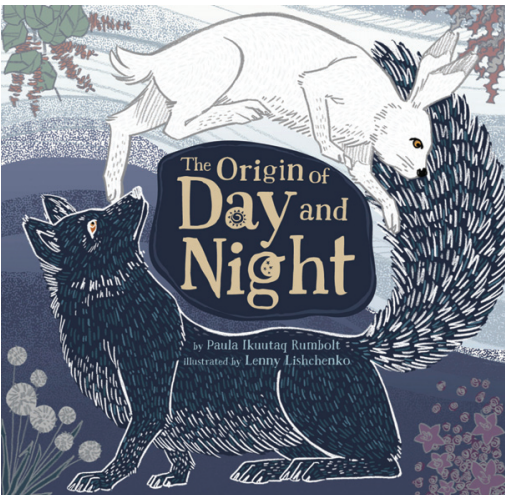
teacher, offers a cadenced retelling here that is illuminated by Lenny Lishchenko's deliberate palette of mostly black and white. For ages 4-9+. 


\section{The Owl and the Two Rabbits}

Nadia Sammurtok

and Marcus Cutler

In this cautionary tale, a hungry owl hunts two rabbits instead of one, with greed leading to his downfall. This book is a creative retelling of an Inuit traditional story. The author was inspired by a version of this story from the Kivalliq region of Nunavut where she grew up. Bright pastel illustrations uplift the more serious story

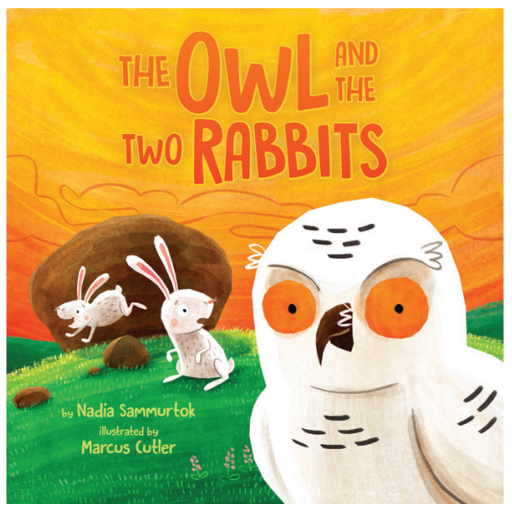
content. For ages 4-8.

\section{Siuluk: The Last Tuniq \\ Nadia Sammurtok \\ and Rob Nix}

This is an inter-generational story that Inuit writer and educator Nadia Sammurtok heard from her father, who heard it from his father. It tells of a man who is said to have been one of the last of the Tuniit to have lived, giants who inhabited the North. A key theme here is accepting others and their individual charac-

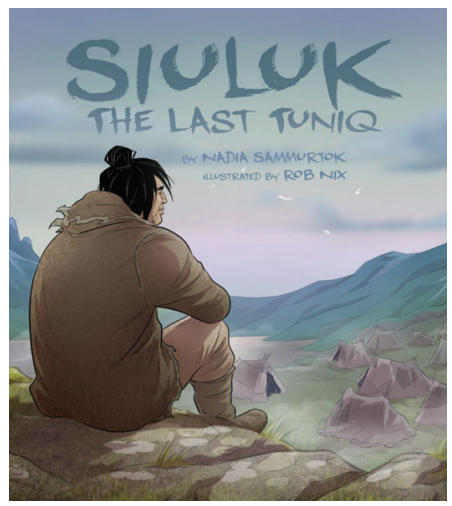
teristics, compatible with the titles in Chapter 2 of this guide. Rob Nix's illustrations depict an engaging comic-book type superhero. A separate, fully Inuktitut version of the story is also available. For ages $4-8+$. 
Wolverine and Little Thunder: An Eel Fishing Story Alan Syliboy

Little Thunder and Wolverine, a trickster, are eel fishing. One night they encounter the giant river eel, and Wolverine triumphs in order to feed their community for the winter. Alan Syliboy is a Mi'kmaq artist who looks to

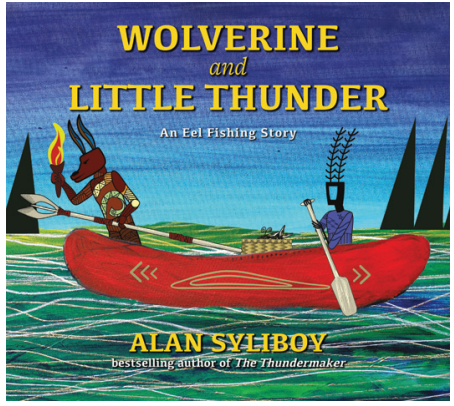
the Indigenous Mi'kmaw petroglyph tradition for inspiration. Here, his mixed-media illustrations incorporate paint on canvas as well as digital elements. For ages $5^{-8}$.

\section{From the Heart of Africa:}

\section{A Book of Wisdom}

collected by Eric Walters

This is a book of 15 aphorisms, or proverbs, with African origins. Each saying is connected to its place of origin as well as defined in childfriendly language. Illustrations, created by artists from countries all over the world, accompany each saying. Author Eric Walters runs Creation of Hope, an organisation that provides

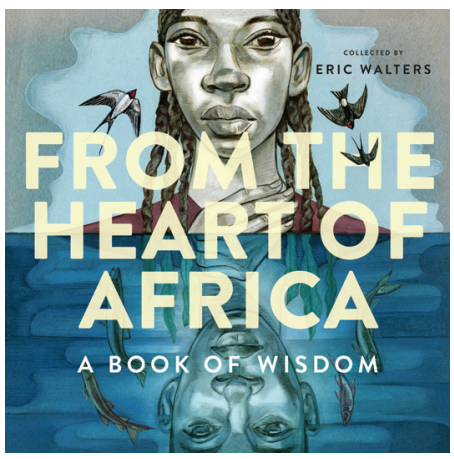
care for orphans in Kenya. For ages 6-adult.

\section{The Wild Beast}

Eric Walters

and Sue Todd

This is a creative retelling of an African story about the wildebeest. In different parts of Eastern and Central Africa, there are many versions of this creation story. In this version, the Creator built this unique animal from particular parts common to other animals. Artist Sue Todd has used lino cut prints with digital colour to create vivid illustrations. For ages $5^{-8}$.

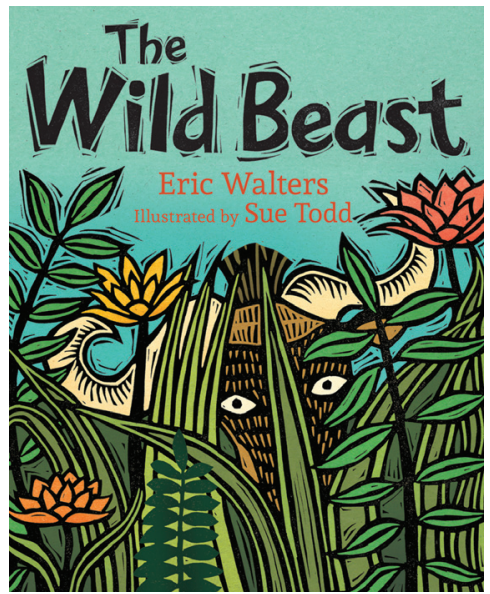




\section{$2 \quad$ Modern Tales Based on Traditional Patterns}

\section{Cinderella and the Furry Slippers}

Davide Cali

and Raphaëlle Barbanègre

This twist on the Cinderella story sees our heroine unhappy with her fairy godmother's magic. When she wins the dance-off, she discovers that she also dislikes the prince. On her way home, she sees a girlsonly career fair and decides to head that way. Raphaëlle Barbanègre's digital illustrations are comedic and bright. For ages $5^{-8+}$.

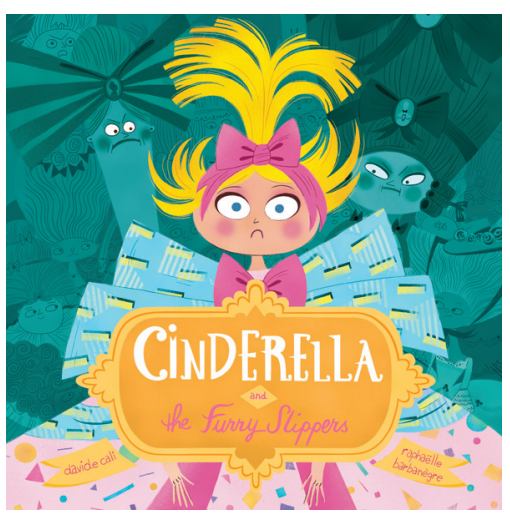

\section{Dancing with Daisy}

Jan L. Coates

and Josée Bisaillon

In this fun-filled, modern pourquoi story, Grampy uses the structure of a tall tale to relate his 1962 experience with Hurricane Daisy. He personifies the storm as a forceful woman trying to get him to be her

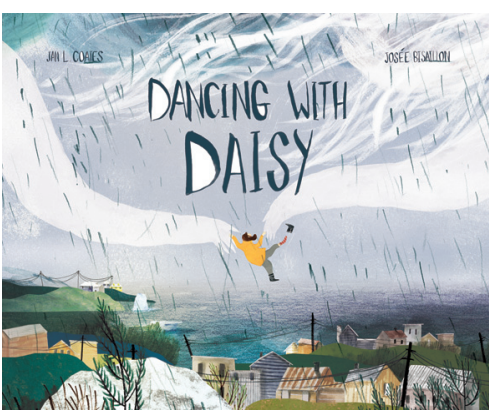
dance partner until, finally, Nana fends her off. The story is presented to his grandson alongside vibrant multimedia illustrations that give a rationale for why Grampy has wrinkles and false teeth. For ages $6-8$.

\section{Song on the Wind}

Caroline Everson

and Anne Marie Bourgeois

This gentle rhyming poem about the journey of a lullaby is beautifully illustrated by Anne Marie Bourgeois whose work is inspired by her Indigenous ancestry. For ages $5^{-8}$. 


\section{Arthur Garber the Harbor Barber}

Joe Frank

This humorous rhyming book presents a series of stories told by a small-town barber about his clients. Some may be real, while others are very likely maritime tall tales. The bold watercolour illustrations are witty and engaging. For ages $5-7$.

\section{When Molly Drew Dogs \\ Deborah Kerbel \\ and Lis Xu}

One night, Molly's chalk drawings come to life and rescue her in the most unexpected way. This engaging book was inspired by the Japanese folktale "The Boy Who Drew Cats." Lis Xu's childlike, coloured-pencil illustrations are dreamy and imaginative. For ages $5^{-8}$.

\section{The Playgrounds of Babel}

JonArno Lawson

and Piet Grobler

The biblical story of the Tower of Babel is adapted here and told through dialogue as one child creatively translates an old woman's messages. This is a book about language and communication. Grobler's mixed-media illustrations use fresh watercolour and coloured pencil for the Babel tale while contrasting the story on the playground by using darker tones.

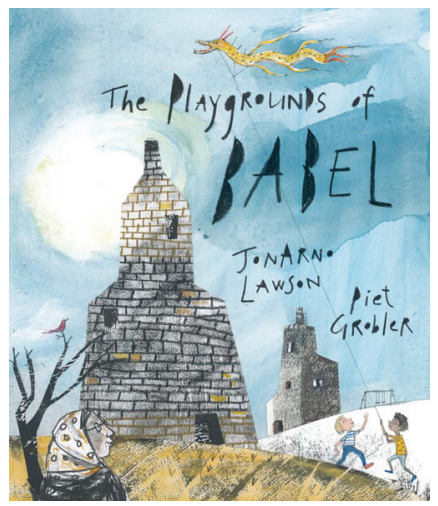
For ages $5^{-9+}$.

\section{The Christmas Wind}

Stephanie Simpson McLellan

and Brooke Kerrigan

One stormy night before Christmas, Jo, her mother, and the newborn baby have to leave their home. They take shelter in a barn but the farmer carries them to refuge inside his house. This poignant picture book echoes the Christian nativity story. Brooke Kerrigan's muted coloured-pencil images and watercolour washes extend the complexity of this story about vulnerability and compassion. For ages $5^{-8+}$. 


\section{The Girl and the Wolf \\ Katherena Vermette \\ and Julie Flett}

This is an original twist on a classic wolf tale. A little girl is gathering berries with her mother when she becomes lost in the woods. When she encounters a wolf, he coaches her to use her wits and eventually she finds her family again. That night she leaves tobacco in a red cloth for the wolf as a gift of thanks. Katherena Vermette is a Métis author from Treaty One territory in Winnipeg and her author's note describes the process she used in retelling a European fairy story "inspired by traditional stories, yes, but in no way taken from one." Julie Flett is a Cree-Métis award-winning artist whose distinctive style is on fine display here. For ages 4-9+.

\section{Bibliography}

*In the spirit of the recommendations of the Truth and Reconciliation Commission, an asterisk appears beside works created by Indigenous writers or artists.

Cali, Davide (illustrated by Raphaëlle Barbanègre) (2017). Cinderella and the Furry Slippers. Toronto, ON: Tundra Books/Penguin Random House.

Coates, Jan (illustrated by Josée Bisaillon) (2019). Dancing with Daisy. Tors Cove, NL: Running the Goat/Books \& Broadsides.

*Deer, Beatrice (illustrated by D. J. Herron) (2019). The Fox Wife. Iqaluit, NU: Inhabit Media.

Dinn, Philip \& Jones, Andy, adapted from a tale told by Mrs. Elizabeth Brewster (illustrated by Denise Gallagher) (2019). Peg Bearskin: A Traditional Newfoundland Tale. Tors Cove, NL: Running the Goat/Books \& Broadsides.

*Dodge, Sandra L. (translated by Georgina Francis) (2017). Minegoo Mniku: the Mi'kmaq Creation Story of Prince Edward Island=Epekewitkewey A'tukwaqn. Charlottetown, PEI: Acorn Press.

*Everson, Caroline (illustrated by Anne Marie Bourgeois) (2018). Song on the Wind. Markham, ON: Fifth House.

Frank, Joe (2019). Arthur Garber the Harbor Barber. Richmond Hill, ON: Firefly Books.

*Goose, Roy \& McCluskey, Kerry (illustrated by Soyeon Kim) (2017). Sukaq and the Raven. Iqaluit, NU: Inhabit Media.

*Harper, Maika (illustrated by Marcus Cutler) (2019). The Walrus and the Caribou. Iqaluit, NU: Inhabit Media. 
*Jaadee, Kung (illustrated by Jessika von Innerebner) (2019). Gifts from Raven. Victoria, BC: Medicine Wheel Education.

Kerbel, Deborah (illustrated by Lis Xu) (2019). When Molly Drew Dogs. Toronto, ON: Owlkids Books.

*Larsen-Jonasson, Theresa "Corky" (illustrated by Jessika von Innerebner) (2019). The Circle of Caring and Sharing. Victoria, BC: Medicine Wheel Education.

Lawson, JonArno (illustrated by Piet Grobler) (2019). The Playgrounds of Babel. Toronto, ON: Groundwood Books/House of Anansi Press.

MacKay, Elly (2018). Red Sky at Night. Toronto, ON: Tundra Books/Penguin Random House.

McLellan, Stephanie Simpson (illustrated by Brooke Kerrigan) (2017). The Christmas Wind. Markham, ON: Red Deer Press.

Paniaq, Herve (illustrated by Germaine Arnaktauyok) (2018). Takannaaluk. Iqaluit, NU: Inhabit Media.

*Rumbolt, Paula Ikuutaq (illustrated by Lenny Lishchenko) (2018). The Origin of Day and Night. Iqaluit, NU: Inhabit Media.

*Sammurtok, Nadia (illustrated by Marcus Cutler) (2019). The Owl and the Two Rabbits. Iqualuit, NU: Inhabit Media.

*Sammurtok, Nadia (illustrated by Rob Nix) (2018). Siuluk the Last Tuniq. Iqaluit, NU: Inhabit Media.

*Syliboy, Alan (2019). Wolverine and Little Thunder: An Eel Fishing Story. Halifax, NS: Nimbus Publishing.

*Vermette, Katherena (illustrated by Julie Flett) (2019). The Girl and the Wolf. Penticton, BC: Theytus Books.

Walters, Eric (Ed.) (2018). From the Heart of Africa: A Book of Wisdom. Toronto, ON: Tundra Books/Penguin Random House.

Walters, Eric (illustrated by Sue Todd) (2018). The Wild Beast. Victoria, BC: Orca Book Publishers. 